\title{
A Scoping Review of Ultrasound Teaching in Undergraduate Medical Education
}

\author{
John Birrane ${ }^{1} \cdot$ Hafiza Misran ${ }^{2} \cdot$ Moninne Creaney $^{2} \cdot$ George Shorten $^{3} \cdot$ \\ Catherine Moyra Nix ${ }^{2,4}$
}

Published online: 8 November 2017

(C) The Author(s) 2017. This article is an open access publication

\begin{abstract}
Introduction Increasingly, medical schools are integrating Point of Care Ultrasound (POCUS) into their curricula. This review investigated the available literature on how best to integrate POCUS in the teaching of medical students and the benefits of doing so.

Methods Given the heterogeneous literature that has emerged on POCUS education, a scoping review was conducted. Relevant medical databases, including PubMed, MEDLINE, PsycINFO, EMBASE and CINAHL, were searched between January 1980 and August 2016, using keywords identified by the authors. Inclusion criteria were as follows: prospective or retrospective studies, observational or intervention studies, and studies describing how medical students learn to use ultrasound.

Results The literature search yielded 593 articles, of which 128 met the inclusion criteria. Studies that met the inclusion criteria were sub-categorised under the following headings: those that described or evaluated an ultrasound curriculum, those that employed ultrasound as a means of teaching another topic in the curriculum (i.e., anatomy, physical examination,
\end{abstract}

Electronic supplementary material The online version of this article (https://doi.org/10.1007/s40670-017-0491-4) contains supplementary material, which is available to authorized users.

Catherine Moyra Nix

catherine.nix@ul.ie

1 School of Medicine, NUI Galway, Galway, Ireland

2 Department of Anaesthesia \& Critical Care Medicine, University Hospital Limerick, Limerick, Ireland

3 Department of Anaesthesia, University College Cork, Cork, Ireland

4 Department of Anaesthesia, University of Toronto, Toronto, ON, Canada physiology, invasive procedures), those that investigated the learning curve of ultrasound education and those that employed adjuncts or peer mentoring to teach ultrasound.

Conclusions The reviewed literature indicates that the integration of ultrasound in undergraduate medical education is both feasible and beneficial to medical students. This article is intended to inform medical educators aiming to integrate ultrasound into their medical school curricula.

Keywords Medical education - Curriculum evaluation . Undergraduate teaching $\cdot$ Ultrasound education $\cdot$ Point of care ultrasound (POCUS)

\section{Introduction}

Training programs in ultrasound (particularly point of care ultrasound (POCUS)) are already well-established for postgraduate medical practitioners [1]. More recently, undergraduate medical programs are integrating ultrasound (US) into their curricula. The Ultrasound in Medical Education Portal lists over 200 medical schools on the AIUM (American Institute of Ultrasound Medicine) website as having a curriculum which includes an ultrasound component [2]. In 2014, the American Academy of Emergency Medicine issued a clinical practice statement declaring that 'Ultrasound should be integrated into undergraduate medical education curricula' [3]. The purpose of this study is to provide a guide for medical educators of the available evidence regarding how best to integrate ultrasound (e.g., correlating human anatomy with corresponding ultrasound images or sonoanatomy) and the possible learning opportunities associated with it (e.g., using it as a teaching tool to demonstrate blood flow or focusing on 
its clinical applications). We aimed to inform medical educators of the following:

(i) the different categories of literature available on the topic of undergraduate ultrasound

(ii) findings of importance from researchers in this field

(iii) future directions for ultrasound in undergraduate medical education

Given the heterogeneous literature that has emerged in this field, a scoping review was conducted. Scoping reviews differ from systematic reviews in that they have a broader focus and are often employed as a means of defining the parameters of the literature on a given subject [4].

\section{Methods}

Data Sources and Searches A search of electronic databases (Pubmed, EMBASE, CINAHL, Medline, PyscINFO) was conducted for educational studies published between January 1980 and August 2016 that either directly taught medical students the use of ultrasound or that reviewed an ultrasound program for medical students. Search terms were combined as per Table 1. Hand searched articles, including articles we found while examining reference lists from identified primary papers, were also examined for inclusion.

Study Selection The process for article screening is outlined in the PRISMA flow (Fig. 1). Only full-length articles published in English were considered for inclusion. Duplicate articles within or between databases were excluded with the help of the referencing software Endnote (version X7.4). The remaining full-text articles were screened independently for inclusion by two reviewers (CN, JB). Discrepancies between reviewers were resolved through consensus. Inclusion criteria were prospective or retrospective studies, observational or intervention studies and studies describing how medical students learn to use ultrasound. Articles were excluded as per the PRISMA flow (Fig. 1; for citation references, see Appendix A). Studies that met the inclusion criteria were reviewed by two reviewers $(\mathrm{CN}, \mathrm{JB})$ for thematic commonalities. Once categories were formulated the major findings from these categories were discerned and discussed.

\section{Results}

The literature search yielded 593 articles, of which 128 were considered eligible for inclusion.

The categories that emerged were as follows: papers that described or evaluated an ultrasound curriculum and papers that surveyed those involved in the development and evaluation of these curricula; those that employed ultrasound as a means of teaching another topic in the curriculum (e.g., anatomy, physiology, physical examination, invasive procedures); articles that examined the learning curve for undergraduate ultrasound and articles that described the use of adjunctive methods or technology in the teaching of ultrasound to medical students, including those which used peer mentoring. Where papers featured elements of more than one category, they were classified with respect to the category that best fitted the primary focus of the paper. Tables (1, 2, 3, 4 and 5) are presented for each category.

\section{Curriculum}

Papers categorised in the curriculum category either described a fully-formed ultrasound curriculum or described

Table 1 Literature search terms

$A N D$

$\longrightarrow$

Medical students Education Ultrasound

\begin{tabular}{|c|c|c|c|}
\hline \multirow[t]{3}{*}{$O R$} & \multirow{2}{*}{$\begin{array}{l}\text { "medical students" } \\
\text { "pre residence" }\end{array}$} & Education & "ultrasound guided" \\
\hline & & Teaching & \multirow[t]{2}{*}{ Ultrasound } \\
\hline & "medical school" & "medical school" & \\
\hline
\end{tabular}


Fig. 1 PRISMA flow of literature search

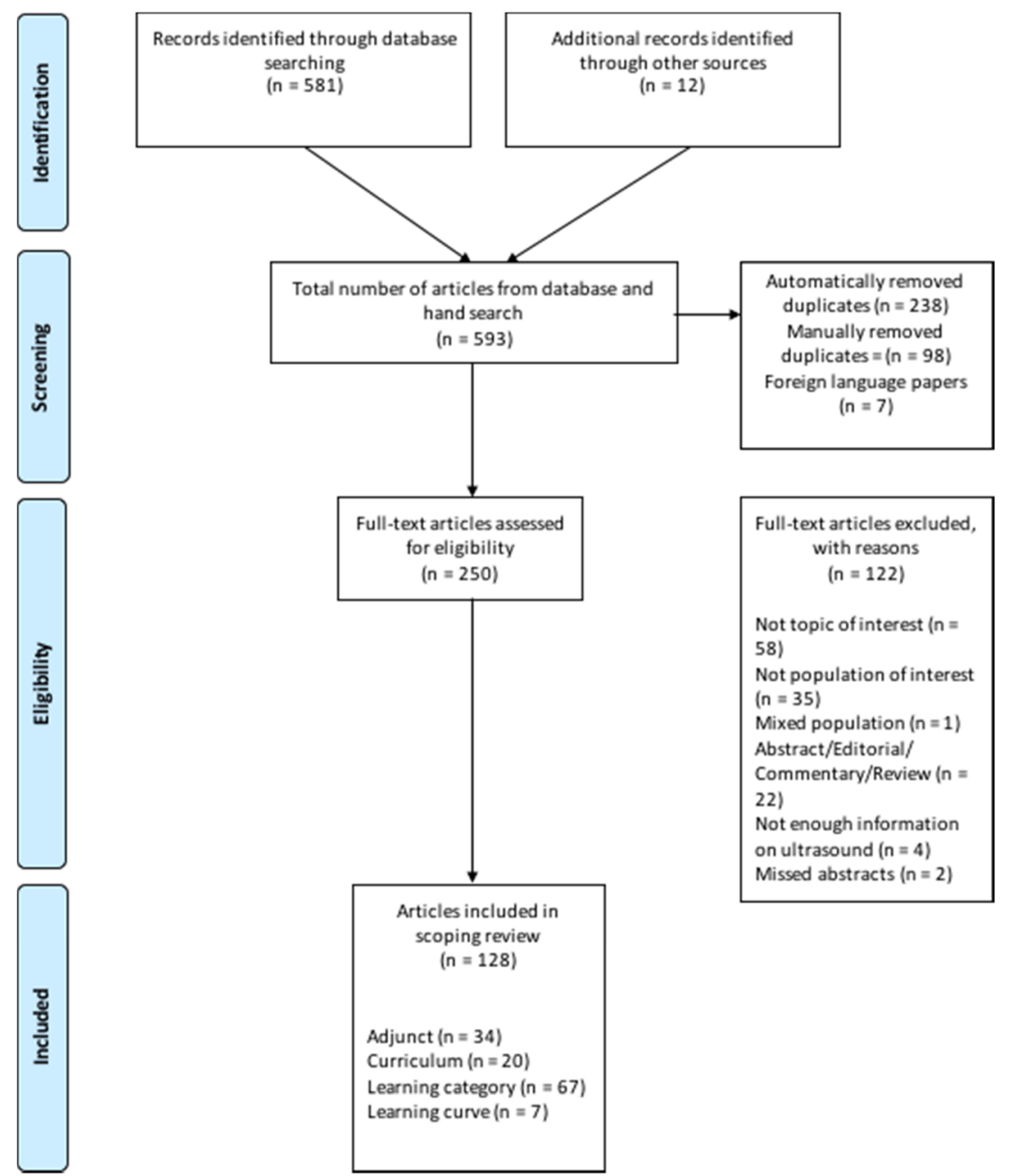

an ultrasound teaching intervention that spanned more than a single educational theme or goal. We also included in this section papers that surveyed ultrasound educators with respect to ultrasound implementation or assessment in medical schools.

\section{Learning Category_-Incorporation of Ultrasound into Teaching of Another Curriculum Topic}

Sixty-seven papers were categorised as incorporating US into teaching a particular part of the curriculum. Some

Table 2 Curriculum papers - 20 papers

\begin{tabular}{|c|c|c|}
\hline Sub-category & Citation reference & Description of subcategory \\
\hline $\begin{array}{l}\text { Curriculum description } \\
\text { or evaluation }\end{array}$ & {$[5-19]$} & $\begin{array}{l}\text { Fifteen papers describe variously integrated ultrasound curricula. Five studies are notable for the } \\
\text { numbers of medical students involved in a formal evaluative process }(>150)[5-9] \text {. Heinzow et } \\
\text { al. [5] reported that students were evaluated as per DEGUM standards (national sonographer } \\
\text { examination standards). Hoppmann et al. [10] published a review of their integrated ultrasound } \\
\text { curriculum and is notable for the practical advice it offers educators starting their own ultrasound } \\
\text { curriculum. Their } 2015 \text { follow-up article details recommendations for student assessment and } \\
\text { the value of an US image review portal [11]. Most papers are emergency medicine-led. Two } \\
\text { papers }[9,16] \text { are radiology-led. }\end{array}$ \\
\hline $\begin{array}{l}\text { Curriculum } \\
\text { surveys }\end{array}$ & {$[20-24]$} & $\begin{array}{l}\text { Five papers featured surveys of curriculum administrators regarding incorporation of ultrasound into } \\
\text { medical schools in the USA. Bahner [20] provides a useful cross-section of ultrasound teaching in } \\
\text { the USA, where } 62.2 \% \text { of schools that responded reported that ultrasound was a part of their } \\
\text { medical school curriculum. Two papers surveyed ultrasound experts using a 'Delphi' } \\
\text { methodology to establish ultrasound learning milestones [21] and an assessment tool [22]. }\end{array}$ \\
\hline
\end{tabular}


Table 3 Learning category-67 papers

\begin{tabular}{|c|c|c|}
\hline Sub-category & Citation reference & Description of subcategory \\
\hline Anatomy & {$[25-40]$} & $\begin{array}{l}\text { Ultrasound has been highlighted as an effective means of teaching clinically encountered, 'living' } \\
\text { anatomy, as distinct from traditional cadaver or textbook based methods [25-30]. US supported } \\
\text { teaching addressed cardiac anatomy [33-35] most commonly, and several other organ systems } \\
{[30,32,36] \text {. Moscova et al. [37] found that students' perception of the ultrasound in the anatomy }} \\
\text { course varied with prior anatomical knowledge. }\end{array}$ \\
\hline
\end{tabular}

Physiology [41-44]

Brunner et al. [41] reported positive subjective feedback by students to the integration of echocardiography into their teaching of cardiac physiology to medical students. Bell, Wilson and Hoppmann [42] found that students taught cardiac physiology with the help of ultrasound significantly improved their scores on an exam on that topic. Paginini and Rubini [43] describe the integration of a lung ultrasound demonstration to a lecture on lung physiology. In 2016, they reported another lecture [44], this time demonstrating vascular physiologic and cardiovascular reflexes. Both lectures received positive subjective evaluations from students.

Physical examination $\quad[45-81]$

The potential to incorporate ultrasound into physical examination teaching led Fox [45] to develop the 'UCI 30'. This is a set of ultrasound examinations that parallel the 'Stanford 25', a set of core physical examinations that institutions recommend should be familiar to students. Dinh et al. [46] found that students that had ultrasound incorporated into their physical examination curriculum obtained greater OSCE scores than a cohort of students that took the exams prior to the introduction of ultrasound, in the same medical school.

The educational interventions found here range from those that teach students to scan a wide range of anatomy [47, 48] or regional anatomy [49] to more focused exams of the vascular [50-52], abdominal [53-55], head and neck [56], cardiac [57, 58] and respiratory [59] systems. Some institutions taught students ultrasound-specific protocols such as FAST [60-62] or USEFUL [63] scans.

Senior medical students, whose learning objectives have graduated to the diagnosing of disease in real-world patients, have demonstrated significant improvement in their ability to diagnose disease following brief, focused ultrasound teaching programs [64-68]. These benefits are particularly impressive when benchmarked against postgraduate medical practitioners using either physical examination $[69,70]$ or ultrasound $[71,72]$. The obstetric ultrasound study of Hamza et al. is notable for its use German Society of Ultrasound in Medicine (DEGUM) guidelines as the source material for student teaching, and for its use of a standardised teaching approach [73]. Amini et al. [74] report the teaching of ultrasound centred around a clinical problem-based theme, that of hypotension. The intervention taught students about the ultrasound diagnosis of common pathologies that cause hypotension, including pulmonary embolism, pneumothorax and abdominal aortic aneurysm.

Procedures [82-91]

Ultrasound has been used in conjunction with 'phantom' simulators [82-85] or cadavers [86, 87] to teach invasive procedures such as venous and arterial line placement and nerve blocks. McCrary et al. [88] used a fresh cadaver model to teach ultrasound-guided breast biopsy to medical students on surgery clerkship. Two studies $[84,85]$ used a randomised group methods to assess differences between ultrasound or landmark-based methods of teaching venous catheter placement. Griswold-Theodorson [85] found that students were safer and more successful when using ultrasound guidance, whereas Osborn et al. [84] demonstrated no difference in success rates, although students' subjective ratings of knowledge gain and ease of use were greater in those who had undergone US-based teaching.

Table 4 Learning Curve — seven papers

Citation Description of subcategory

[92-98] Training medical students in POCUS for 1 year appears to provide them with a significant advantage in the postgraduate arena [92]. Retention of knowledge can be problematic (one paper reported a 17\% decrease in knowledge learned after 1 year). Medical students in this study achieved scores that were $55 \%$ greater than those of their US-naïve counterparts in an US OSCE [92]. Small group teaching is associated with better knowledge retention [93]. Low fidelity models are sufficient for improving hand-eye co-ordination prior to procedures on patients [94]. The learning curve to enable novices to detect major cardiac abnormalities with acceptable diagnostic value when compared with experienced echocardiographer findings is short [95]. Ultrasound 'knobology' has been shown to be responsible for a large portion of the cognitive load for novice ultrasound learners [96, 97]. Gradl-Dietsch et al. [98] found no effect of gender on either objective performance during assessment or subjective preference when learning ultrasound. 
Table 5 Adjunct category—34 papers

$\begin{array}{lll}\text { Sub-category } & \begin{array}{l}\text { Citation } \\ \text { reference }\end{array} & \text { Description of subcategory }\end{array}$

Social and event-based [99-103] adjuncts

Devices and simulators $\quad[104-116]$

Online and e-learning $\quad[117,118]$ technologies

Novel teaching techniques

Peer-mentoring

[126-132]
The use of ultrasound-themed events and competitions has been employed as an adjunct to stimulate student interest and enthusiasm in ultrasound [99-101]. Two papers in our search detail social groups centred on an interest in ultrasound. One was student-led [102], the other was delivered through social media [103]. Both are discussed in terms of opportunities for stimulating student engagement and interest.

The primary objective of these papers was to describe or evaluate ultrasound simulators (or 'phantoms') or devices adjunctive to the ultrasound machine itself. Ultrasound simulators are models of human anatomy designed to provide a means of practicing ultrasound skills where practice on a human is impractical, dangerous or unethical. Our search found studies that tested both commercially available simulators [104-108] and institutions that built their own simulators with varying degrees of complexity [109-111]. Many of the simulators available work by linking movements of a 'dummy' ultrasound probe on a non-human model with a 3D imaging dataset, linking real-time changes in the image visible on-screen with hand movements. Three papers in this category used a randomised method in comparing simulators with live patients in the teaching of ultrasonography to medical students. Both Bentley et al. [105] and Damewood et al. [108] randomly allocated students to be taught the FAST scan using either a human model or a simulator; both groups of students were then evaluated in their ability to perform a FAST scan on a live patient, post-intervention. No significant difference in OSCE scores was found between the two groups in either study. However, Moak et al. [106] found that students trained with a simulator demonstrated poorer scanning technique and image acquisition than those that trained with live models when learning transvaginal sonography. Kusonose et al. [104] randomly allocated students to take part in either a simulator-based training course or textbook-based learning prior to undergoing hands-on ultrasound training. Simulator-trained participants scored better in the quality of image obtained in each of the seven transthoracic echocardiography views.

Guidance systems for ultrasound-guided vascular access have been shown to reduce procedure times [112-114], and the learning curve [112] for medical students. These technologies may provide a 'safe space' in which students can learn the fundamentals of ultrasound-guided vascular access before attempting such procedures on patients.

Benninger [115] combined an ultrasound finger probe and Google Glass to integrate ultrasound visualisation with physical palpation. Sheehan et al. [116] reported that remote (telemedicine) feedback could be used to improve student performance of ultrasound versus verbal direction.

In a written exam taken prior to a hands-on ultrasound course, Hempel et al. [117] report that students who took part in a case-based e-learning course performed better than those who were taught with a classroom-based presentation; Hughes et al. [118] described benefits for students in collating a portfolio of ultrasound images as a means of tracking their learning and development.

This category describes papers in which a novel teaching technique was itself the primary focus of the paper. Learning benefits are reported for practicing in pairs instead of alone [120]; physician-patient role play [121]; students learning about ultrasound through their participation as simulated patients [122] and the equivalence of self-directed podcasts as a didactic learning method compared with lectures [123]. Some educators have trialled enhanced ultrasound images through fusing US images with MRI, or the employment of simple line drawings to provide a reference for the 2D sonoanatomy images [124]. These are all measures that educators can consider as a low-cost means of enhancing ultrasound teaching.

In the course of evaluating articles which integrate POCUS in a novel way, peer mentoring emerged as a major theme in ultrasound education. In the peer mentoring studies reviewed, medical students in clinical or clerkship years (typically third or fourth year) teach preclinical medical students (first or second year). The utilisation of peer mentors in ultrasound education programs has been proposed as a means of decreasing the number of senior faculty required to deliver ultrasound education to medical students, thus allowing education to take place in staff or resource-deprived settings [126]. Advantages for the education of medical students also extend to the peer tutors themselves $[127,128]$. There may, however, be a limit to the extent to which peer tutoring can replace faculty instruction, with Kühl et al. [129] finding student's knowledge gains to be less when taught by peer mentors compared with faculty. Though this point is contradicted by Knobe et al.'s [128] randomised controlled trial, subjective feedback in this and Dickerson et al.'s study [130] show that not all students find peer teaching as acceptable as that delivered by faculty. authors have described POCUS as the 'new stethoscope' [119] and the majority of the papers which focus on a curriculum topic have taught ultrasound in the context of physical examination (31 papers). Fifteen papers focus on the teaching of sonoanatomy while smaller numbers focus on the topics of physiology and invasive procedures. 


\section{The Learning Curve for Undergraduate Ultrasound Education}

The learning curve category includes papers that either inform educators regarding factors that enhance or limit student learning ultrasound, or formally examine the learning curve for the acquisition of ultrasound skills.

\section{Adjunctive Technologies and Teaching Methods in Undergraduate Ultrasound Education}

The adjunct category comprises papers that describe or evaluate adjunctive technologies and teaching methodologies in the teaching of ultrasound to undergraduates.

\section{Discussion}

Our review of the current literature on the integration of US into medical school curricula found that the published research is focused on the following four areas:

(1) Descriptions of various fully and partially integrated ultrasound curricula where ultrasound has been integrated into two or more years of the medical school curriculum. A small number of these programs include objective evaluation. In addition, surveys of program administrators are available, giving insights into the process of successfully integrating ultrasound into an undergraduate medical curriculum.

(2) Descriptions of the incorporation of ultrasound into one topic in the curriculum (i.e., anatomy, physiology, physical examination, invasive procedures). Some authors included an evaluation of these educational interventions.

(3) Descriptions of the learning curve of ultrasound education

(4) Descriptions and evaluations of using adjuncts or peer mentoring to teach US.

Six take home messages from this scoping review:

1. Integrate Ultrasound into the Undergraduate Medical Curriculum - 'Just Do It'

The major difference in the papers categorised to category 1 or 2 is one of scale. Incorporation of ultrasound into an entire curriculum is a much larger undertaking than standalone additions to parts of a curriculum. The latter can be achieved in lower-resourced settings but the former, while resource intensive, leads to a more robust program. Twenty-one percent of the papers in this review ( 27 of 128 publications) have involved three authors from three different institutions that have integrated ultrasound teaching within each year of their medical school curriculum (DP Bahner, JC Fox and RA Hoppmann). Full integration has allowed for the development of such programs over time, with incorporation of feedback and continued improvement $[10,11]$.

The investment of these medical schools in ultrasound is being rewarded by increased student interest, with some evidence emerging that medical students are choosing programs based on their investment in ultrasound [11] leading to our first take home message which is 'Integrate ultrasound into your undergraduate medical curriculum'. If possible, invest in a fully integrated program. Such programs do require a significant initial investment in terms of faculty, equipment and administration; however, if your medical school does not have the resources for this initial investment, the evidence is there to support integrating ultrasound into one topic in the curriculum such as anatomy and building out from this as resources allow. A recurring theme in the papers that employed ultrasound to teach anatomy was the use of ultrasound to teach 'living anatomy' [25-27].

The majority of papers in this scoping review (67/128) described the use of ultrasound as a tool to enhance the teaching of another topic or a clinical skill.

2. Evaluate your program objectively and incorporate an image management system.

Objective measures of ultrasound performance have been developed but have yet to be validated in the undergraduate population. The majority of papers that we reviewed were satisfied to rely on students' subjective ratings of their own learning experiences. The limitations of such data are clear: students may rate a course as favourable even where their knowledge gains were modest and no reliable comparison is possible between the effectiveness of the various educational interventions described. Students tend to overestimate their performance, but a significant amount of knowledge can be retained at 8 months in a well-structured program [8].

One way of assessing students is to use the national sonographer standard [5]; however, this standard will vary between countries. Although medical students can reach national sonographer standards with a structured integrated approach [5], the majority of student scores tended to be akin to 'a borderline level of competency'. This underscores the need for a structured approach to undergraduate ultrasound education which incorporates a robust image review and management system [15]. Many programs up to this point have been evaluated using various pre- and post-test questionnaires, MCQ exams and checklists; however, validated tools are emerging $[21,22]$.

In 2013, Tolsgaard et al. achieved international consensus across multiple specialties on a generic ultrasound rating scale using a Delphi technique [133]. In 2014, Tolsgaard et al. 
published their assessment of 30 ultrasound users. They used their OSAUS scale (Objective Structured Assessment of Ultrasound Skills) to successfully differentiate novice, intermediate and experienced obstetric and gynaecology physician ultrasound users [134]. In 2015, Todsen et al. replicated this work for point of care ultrasound in a group of 24 physician participants [135]. The OSAUS has yet to be validated in the undergraduate population. Our research group believes this is the next step to advance the field of undergraduate ultrasound education.

3. Involve the right people - include emergency physicians, radiologists, sonographers and clinicians who use ultrasound on a daily basis. Consider the value of peerteaching.

Currently, the majority of programs are led by emergency medicine faculty but there is a growing engagement of radiologists in undergraduate ultrasound teaching [23]. Given the already high demands on faculty for teaching time, institutions should consider enlisting the help of ultrasound professionals such as sonographers, or peer teachers. Near peer teaching offers an opportunity for advanced students to push their learning horizons further, while also relieving an oft-cited limitation in ultrasound program construction - the availability of qualified faculty that can meet a large teaching commitment [126].

4. Ultrasound simulators and phantoms are versatile adjuncts that allow for ultrasound teaching in the absence of patients or cadavers

Some of the most common teaching adjuncts employed in the ultrasound literature were ultrasound simulators and phantoms. The evidence supports the use of simulators as well as several novel low-cost teaching tools for the less well-resourced educator. Ultrasound can also complement cadaver-based teaching, allowing invasive interventional skills (central line placement $[85,86]$, pericardiocentesis [87], surgical biopsy [88]) to be taught on realistic anatomy without compromising patient safety. Where cadavers are not available, ultrasound simulators and phantoms can fulfil a similar role.

5. Use small group teaching and spend some time on knobology and physics - this accounts for a significant cognitive load for novices

Ultrasound is operator-dependent; however, students can learn quickly [8], particularly with small-group teaching [93]. Jamnickzky et al. [97] highlighted the cognitive load imposed by ultrasound 'knobology' on novice learners, a finding which serves as a warning to educators that teaching the basics of the technology cannot be sacrificed, even in a timelimited setting.

\section{Harness student enthusiasm}

One constant among the heterogeneous literature reviewed here was in students' responses to ultrasound teaching. In every paper in which students' subjective assessment of ultrasound incorporation into the curriculum was sought, it was very positive. The benefits of active student engagement and leadership have also been demonstrated in student-led ultrasound interest groups [102], where students interested in ultrasound have the opportunity to organise educational events and demonstrate autonomy in their learning. Medical students respond positively to US and, after receiving undergraduate ultrasound instruction, are more likely to use US in their postgraduate practice [24].

\section{Conclusions and Future Directions}

Integration of ultrasound into the medical school curriculum is feasible and beneficial to medical students. Those programs with greater integration deliver a more robust ultrasound education. The quality of an ultrasound curriculum is dependent on involving a wide range of ultrasound practitioners, from radiology faculty to peer teaching. Ingenuity in teaching technologies and strategies, including the use of low-cost simulators and near peer teaching, has provided an example of how ultrasound can be taught, even in less well-resourced medical schools.

The following gaps exist: (1) Long-term follow-up studies demonstrating that learners improve with existing teaching methods and (2) the use of validated tools (such as OSAUS) to assess learners and programs.

Ultrasound education researchers should look to the established medical education literature to design follow-up studies which can demonstrate that structured training programs improve the ultrasound skills of students. The authors agree with Hoppmann et al.'s [11] call for 'an international consensus conference on US education to help define the essential elements of US education globally to ensure US is taught and ultimately practiced to its full potential'.

\section{Limitations of This Paper}

Limitations of space precluded a comprehensive analysis of each paper uncovered in our search. For this same reason, papers were generally only reported in the category that best fitted their primary focus. For example, a teaching intervention for physical examination that had, as a component, an elearning module or a simulator was categorised under the 
physical examination heading and not in terms of the adjunctive technologies employed.

Acknowledgements The authors are grateful to Professor Brian Kavanagh and Ms. Brittany Rosenbloom.

Open Access This article is distributed under the terms of the Creative Commons Attribution 4.0 International License (http:// creativecommons.org/licenses/by/4.0/), which permits unrestricted use, distribution, and reproduction in any medium, provided you give appropriate credit to the original author(s) and the source, provide a link to the Creative Commons license, and indicate if changes were made.

\section{References}

1. Nix CM, Margarido CB, Awad IT, Avila A, Cheung JJ, Dubrowski A, et al. A scoping review of the evidence for teaching ultrasoundguided regional anesthesia. Reg Anesth Pain Med. 2013;38(6):47180. https://doi.org/10.1097/AAP.0b013e3182a4ed7a.

2. Medicine AIoUi. Ultrasound in Medical Education Portal. 2017. http://meded.aium.org/.

3. Mills LD SZ. AAEM Clinical Practice Committee Statement. 2014. http://www.aaem.org/UserFiles/UltrasoundCPCStatement.pdf.

4. Armstrong R, Hall BJ, Doyle J, Waters E. Cochrane update. 'Scoping the scope' of a cochrane review. J Public Health. 2011;33(1):147-50. https://doi.org/10.1093/pubmed/fdr015.

5. Heinzow HS, Friederichs H, Lenz P, Schmedt A, Becker JC, Hengst $\mathrm{K}$, et al. Teaching ultrasound in a curricular course according to certified EFSUMB standards during undergraduate medical education: a prospective study. BMC Med Educ. 2013;13(1):84. https://doi.org/10.1186/1472-6920-13-84.

6. Nelson BP, Hojsak J, Dei Rossi E, Karani R, Narula J. Seeing is believing: evaluating a point-of-care ultrasound curriculum for 1st-year medical students. Teach Learn Med. 2016;1-8. https:// doi.org/10.1080/10401334.2016.1172012.

7. Rao S, van Holsbeeck L, Musial JL, Parker A, Antonio Bouffard J, Bridge P, et al. A pilot study of comprehensive ultrasound education at the Wayne State University School of Medicine. J Ultrasound Med. 2008;27(5):745-9.

8. Steinmetz P, Oleskevich S, Lewis J. Acquisition and long-term retention of bedside ultrasound skills in first-year medical students. J Ultrasound Med. 2016;35:1967-75. https://doi.org/10. 7863/ultra.15.09088.

9. Webb EM, Cotton JB, Kane K, Straus CM, Topp KS, Naeger DM. Teaching point of care ultrasound skills in medical school. Acad Radiol. 2014;21(7):893-901. https://doi.org/10.1016/j.acra.2014. 03.001 .

10. Hoppmann RA, Rao VV, Poston MB, Howe DB, Hunt PS, Fowler $\mathrm{SD}$, et al. An integrated ultrasound curriculum (iUSC) for medical students: 4-year experience. Crit Ultrasound J. 2011;3(1):1-12. https://doi.org/10.1007/s13089-011-0052-9.

11. Hoppmann RA, Rao VV, Bell F, Poston MB, Howe DB, Riffle S, et al. The evolution of an integrated ultrasound curriculum (iUSC) for medical students: 9-year experience. Crit Ultrasound J. 2015;7(1):18. https://doi.org/10.1186/s13089-015-0035-3.

12. Amini R, Stolz LA, Gross A, O’Brien K, Panchal AR, Reilly K, et al. Theme-based teaching of point-of-care ultrasound in undergraduate medical education. Intern Emerg Med. 2015;10(5):6138. https://doi.org/10.1007/s11739-015-1222-8.

13. Arger PH, Schultz SM, Sehgal CM, Cary TW, Aronchick J. Teaching medical students diagnostic sonography. J Ultrasound Med. 2005;24(10):1365-9.
14. Bahner DP, Adkins EJ, Hughes D, Barrie M, Boulger CT, Royall NA. Integrated medical school ultrasound: development of an ultrasound vertical curriculum. Crit Ultrasound J. 2013;5(1):6-15. https://doi.org/10.1186/2036-7902-5-6.

15. Bahner DP, Royall NA. Advanced ultrasound training for fourthyear medical students: a novel training program at the Ohio State University College of Medicine. Acad Med. 2013;88(2):206-13. https://doi.org/10.1097/ACM.0b013e31827c562d.

16. Baltarowich OH, Di Salvo DN, Scoutt LM, Brown DL, Cox CW, DiPietro MA, et al. National ultrasound curriculum for medical students. Ultrasound Q. 2014;30(1):13-9. https://doi.org/10.1097/ RUQ.0000000000000066.

17. Blackstock U, Munson J, Szyld D. Bedside ultrasound curriculum for medical students: report of a blended learning curriculum implementation and validation. J Clin Ultrasound. 2015;43(3):13944. https://doi.org/10.1002/jcu.22224.

18. Fox JC, Cusick S, Scruggs W, Henson TW, Anderson CL, Barajas $\mathrm{G}$, et al. Educational assessment of medical student rotation in emergency ultrasound. West J Emerg Med. 2007;8(3):84-7.

19. Kman N, Bernard A, Martin D, Bahner D, Gorgas D, Nagel R, et al. Advanced topics in emergency medicine: curriculum development and initial evaluation. West J Emerg Med. 2011;12(4): 543-50. https://doi.org/10.5811/westjem.2011.2.2095.

20. Bahner DP, Goldman E, Way D, Royall NA, Liu YT. The state of ultrasound education in U.S. medical schools: results of a National Survey. Acad Med. 2014;89(12):1681-6. https://doi.org/10.1097/ ACM.0000000000000414.

21. Dinh VA, Lakoff D, Hess J, Bahner DP, Hoppmann R, Blaivas M, et al. Medical student core clinical ultrasound milestones: a consensus among directors in the United States. J Ultrasound Med. 2016;35:421-34. https://doi.org/10.7863/ultra.15.07080.

22. Black H, Sheppard G, Metcalfe B, Stone-McLean J, McCarthy H, Dubrowski A. Expert facilitated development of an objective assessment tool for point-of-care ultrasound performance in undergraduate medical education. Cureus. 2016;8(6):e636. https://doi. org/10.7759/cureus.636.

23. Phelps A, Wan J, Straus C, Naeger DM, Webb EM. Incorporation of ultrasound education into medical school curricula: survey of directors of medical student education in radiology. Acad Radiol. 2016;23(7):830-5. https://doi.org/10.1016/j.acra.2016.02.012.

24. Prats MI, Royall NA, Panchal AR, Way DP, Bahner DP. Outcomes of an advanced ultrasound elective: preparing medical students for residency and practice. J Ultrasound Med. 2016;35(5):975-82. https://doi.org/10.7863/ultra.15.06060.

25. Jurjus RA, Dimorier K, Brown K, Slaby F, Shokoohi H, Boniface $\mathrm{K}$, et al. Can anatomists teach living anatomy using ultrasound as a teaching tool? Anat Sci Educ. 2013;7(5):340-9. https://doi.org/10. 1002/ase. 1417.

26. Stringer MD, Duncan LJ, Samalia L. Using real-time ultrasound to teach living anatomy: an alternative model for large classes. N Z Med J. 2012;125(1361):37-45.

27. Ivanusic J, Cowie B, Barrington M. Undergraduate student perceptions of the use of ultrasonography in the study of "living anatomy". Anat Sci Educ. 2010;3(6):318-22. https://doi.org/10. 1002/ase. 180.

28. Tshibwabwa ET, Groves HM. Integration of ultrasound in the education programme in anatomy. Med Educ. 2005;39(11):1148. https://doi.org/10.1111/j.1365-2929.2005.02288.x.

29. Heilo A, Hansen AB, Holck P, Laerum F. Ultrasound 'electronic vivisection' in the teaching of human anatomy for medical students. Eur J Ultrasound. 1997;5(3):203-7. https://doi.org/10. 1016/S0929-8266(97)00015-3.

30. Teichgräber UK, Meyer JM, Poulsen Nautrup C, von Rautenfeld DB. Ultrasound anatomy: a practical teaching system in human gross anatomy. Med Educ. 1996;30(4):296-8. https://doi.org/10. 1111/j.1365-2923.1996.tb00832.x. 
31. Brown B, Adhikari S, Marx J, Lander L, Todd GL. Introduction of ultrasound into gross anatomy curriculum: perceptions of medical students. J Emerg Med. 2012;43(6):1098-102. https://doi.org/10. 1016/j.jemermed.2012.01.041

32. Dreher SM, Dephilip R, Bahner D. Ultrasound exposure during gross anatomy. J Emerg Med. 2014;46(2):231-40. https://doi.org/ 10.1016/j.jemermed.2013.08.028.

33. Finn GM, Sawdon MA, Griksaitis MJ. The additive effect of teaching undergraduate cardiac anatomy using cadavers and ultrasound echocardiography. Eur J Anat. 2012;16(3):199-205.

34. Griksaitis MJ, Sawdon MA, Finn GM. Ultrasound and cadaveric prosections as methods for teaching cardiac anatomy: a comparative study. Anat Sci Educ. 2012;5(1):20-6. https://doi.org/10. 1002/ase. 259

35. Hammoudi N, Arangalage D, Boubrit L, Renaud MC, Isnard R, Collet JP, et al. Ultrasound-based teaching of cardiac anatomy and physiology to undergraduate medical students. Arch Cardiovasc Dis. 2013;106(10):487-91. https://doi.org/10.1016/j.acvd.2013. 06.002 .

36. Zumwalt AC, Luefler RS, Monteiro J, Shaffer K. Building the body: active learning laboratories that emphasize practical aspects of anatomy and integration with radiology. Anat Sci Educ. 2010;3(3):134-40. https://doi.org/10.1002/ase.153.

37. Moscova M, Bryce DA, Sindhusake D, Young N. Integration of medical imaging including ultrasound into a new clinical anatomy curriculum. Anat Sci Educ. 2015;8(3):205-20. https://doi.org/10. 1002/ase. 1481.

38. Knobe M, Carow JB, Ruesseler M, Leu BM, Simon M, Beckers SK, et al. Arthroscopy or ultrasound in undergraduate anatomy education: a randomized cross-over controlled trial. BMC Med Educ. 2012;12(1):85. https://doi.org/10.1186/1472-6920-12-85.

39. Patten D. Using ultrasound to teach anatomy in the undergraduate medical curriculum: an evaluation of the experiences of tutors and medical students. Ultrasound. 2014;23(1):18-28. https://doi.org/ 10.1177/1742271X14542173.

40. Sweetman GM, Crawford G, Hird K, Fear MW. The benefits and limitations of using ultrasonography to supplement anatomical understanding. Anat Sci Educ. 2013;6(3):141-8. https://doi.org/ 10.1002/ase.1327.

41. Brunner M, Moeslinger T, Spieckermann PG. Echocardiography for teaching cardiac physiology in practical student courses. Am J Phys. 1995;268(6 Pt 3):S2-9.

42. Bell FE, Wilson LB, Hoppmann RA. Using ultrasound to teach medical students cardiac physiology. Adv Physiol Educ. 2015;39(4):392-6. https://doi.org/10.1152/advan.00123.2015.

43. Paganini M, Rubini A. Chest ultrasound integrated teaching of respiratory system physiology to medical students: a first experience. Adv Physiol Educ. 2015;39(2):129-30. https://doi.org/10. 1152/advan.00084.2014.

44. Paganini M, Rubini A. Ultrasound-based lectures on cardiovascular physiology and reflexes for medical students. Adv Physiol Educ. 2016;40(2):243-7. https://doi.org/10.1152/advan.00010. 2016.

45. Fox JC, Schlang JR, Maldonado G, Lotfipour S, Clayman RV. Proactive medicine: the "UCI 30," an ultrasound-based clinical initiative from the University of California, Irvine. Acad Med. 2014;89(7):1-6. https://doi.org/10.1097/ACM.0000000000000292.

46. Dinh VA, Frederick J, Bartos R, Shankel TM, Werner L. Effects of ultrasound implementation on physical examination learning and teaching during the first year of medical education. J Ultrasound Med. 2014;34(1):43-50. https://doi.org/10.7863/ultra.34.1.43.

47. Fodor D, Badea R, Poanta L, Dumitrascu DL, Buzoianu aD, Mircea PA. The use of ultrasonography in learning clinical examination - a pilot study involving third year medical students. Med Ultrason. 2012;14(3):177-81.
48. Shapiro RS, Ko PK, Jacobson S. A pilot project to study the use of ultrasonography for teaching physical examination to medical students. Comput Biol Med. 2002;32(6):403-9.

49. Eissa K, Alokla K, Assasa O, Itani A, Shawwa K, Kheir F. Using simulation-based training to incorporate thoracic ultrasound into physical examination. J La State Med Soc. 2015;167(6):264-7.

50. Ahn JS, French AJ, Thiessen MEW, Browne V, Deutchman M, Guiton G, et al. Using ultrasound to enhance medical students' femoral vascular physical examination skills. J Ultrasound Med. 2015;34(10):1771-6. https://doi.org/10.7863/ultra.15.14.11014.

51. Ho AMH, Critchley LAH, Leung JYC, Kan PKY, Au SS, Ng SK, et al. Introducing final-year medical students to pocket-sized ultrasound imaging: teaching transthoracic echocardiography on a 2-week anesthesia rotation. Teach Learn Med. 2015;27(3):30713. https://doi.org/10.1080/10401334.2015.1044657.

52. Wong I, Jayatilleke T, Kendall R, Atkinson P. Feasibility of a focused ultrasound training programme for medical undergraduate students. Clin Teach. 2011;8(1):3-7. https://doi.org/10.1111/j. 1743-498X.2010.00416.x

53. Barloon TJ, Brown BP, Abu-Yousef MM, Ferguson KJ, Schweiger GD, Erkonen WE, et al. Teaching physical examination of the adult liver with use or real-time sonography. Acad Radiol. 1998;5(2):101-3. https://doi.org/10.1016/S10766332(98)80129-3.

54. Butter J, Grant TH, Egan M, Kaye M, Wayne DB, Carrión-Carire $\mathrm{V}$, et al. Does ultrasound training boost year 1 medical student competence and confidence when learning abdominal examination? Med Educ. 2007;41(9):843-8. https://doi.org/10.1111/j. 1365-2923.2007.02848.x.

55. Cheng WC, Lin XZ, Chen CY. Using modern teaching strategies to teach upper abdominal sonography to medical students. J Chin Med Assoc. 2013;76(7):395-400. https://doi.org/10.1016/j.jcma. 2013.03.011.

56. Bernard S, Richardson C, Hamann CR, Lee S, Dinh VA. Head and neck ultrasound education - a multimodal educational approach in the predoctoral setting: a pilot study. J Ultrasound Med. 2015;34(8):1437-43. https://doi.org/10.7863/ultra.34.8.1437.

57. Cawthorn TR, Nickel C, O'Reilly M, Kafka H, Tam JW, Jackson LC, et al. Development and evaluation of methodologies for teaching focused cardiac ultrasound skills to medical students. J Am Soc Echocardiogr. 2014;27(3):302-9. https://doi.org/10. 1016/j.echo.2013.12.006.

58. Wittich CM, Montgomery SC, Neben MA, Palmer BA, Callahan MJ, Seward JB, et al. Teaching cardiovascular anatomy to medical students by using a handheld ultrasound device. JAMA. 2002;288(9):1062-3. https://doi.org/10.1001/jama.288.9.1062.

59. Cuca C, Scheiermann P, Hempel D, Via G, Seibel A, Barth M, et al. Assessment of a new e-learning system on thorax, trachea, and lung ultrasound. Emerg Med Int. 2013;2013:145361. https:// doi.org/10.1155/2013/145361.

60. Shokoohi H, Boniface K, Kaviany P, Armstrong P, Calabrese K, Pourmand A. An experiential learning model facilitates learning of bedside ultrasound by preclinical medical students. J Surg Educ. 2016;73(2):208-14.

61. Gogalniceanu P, Sheena Y, Kashef E, Purkayastha S, Darzi A, Paraskeva P. Is basic emergency ultrasound training feasible as part of standard undergraduate medical education? J Surg Educ. 2010;67(3):152-6. https://doi.org/10.1016/j.jsurg.2010.02.008.

62. Afonso N, Amponsah D, Yang J, Mendez J, Bridge P, Hays G, et al. Adding new tools to the black bag-introduction of ultrasound into the physical diagnosis course. J Gen Intern Med. 2010;25(11): 1248-52. https://doi.org/10.1007/s11606-010-1451-5.

63. Steller J, Russell B, Lotfipour S, Maldonado G, Siepel T, Jakle H, et al. USEFUL: ultrasound exam for underlying lesions incorporated into physical exam. West J Emerg Med. 2014;15(3):260-6. https://doi.org/10.5811/westjem.2013.8.19080. 
64. Andersen GN, Viset A, Mjølstad O, Salvesen Ø, Dalen H, Haugen B. Feasibility and accuracy of point-of-care pocket-size ultrasonography performed by medical students. BMC Med Educ. 2014;14(1):156. https://doi.org/10.1186/1472-6920-14-156.

65. Stokke TM, Ruddox V, Sarvari SI, Otterstad JE, Aune E, Edvardsen T. Brief group training of medical students in focused cardiac ultrasound may improve diagnostic accuracy of physical examination. J Am Soc Echocardiogr. 2014;27(11):1238-46. https://doi.org/10.1016/j.echo.2014.08.001.

66. Shmueli H, Burstein Y, Sagy I, Perry ZH, Ilia R, Henkin Y, et al. Briefly trained medical students can effectively identify rheumatic mitral valve injury using a hand-carried ultrasound. Echocardiography. 2013;30(6):621-6. https://doi.org/10.1111/ echo.12122.

67. Angtuaco TL, Hopkins RH, DuBose TJ, Bursac Z, Angtuaco MJ, Ferris EJ. Sonographic physical diagnosis 101: teaching senior medical students basic ultrasound scanning skills using a compact ultrasound system. Ultrasound Q. 2007;23(2):157-60. https://doi. org/10.1097/01.ruq.0000263847.00185.28.

68. DeCara JM, Kirkpatrick JN, Spencer KT, Ward RP, Kasza K, Furlong K, et al. Use of hand-carried ultrasound devices to augment the accuracy of medical student bedside cardiac diagnoses. J Am Soc Echocardiogr. 2005;18(3):257-63. https://doi.org/10. 1016/j.echo.2004.11.015.

69. Mouratev G, Howe D, Hoppmann R, Poston MB, Reid R, Varnadoe $\mathrm{J}$, et al. Teaching medical students ultrasound to measure liver size: comparison with experienced clinicians using physical examination alone. Teach Learn Med. 2013;25(1):84-8. https://doi.org/10.1080/10401334.2012.741535.

70. Kobal SL, Trento L, Baharami S, Tolstrup K, Naqvi TZ, Cercek B, et al. Comparison of effectiveness of hand-carried ultrasound to bedside cardiovascular physical examination. Am J Cardiol. 2005;96(7):1002-6. https://doi.org/10.1016/j.amjcard.2005.05. 060.

71. Panoulas VF, Daigeler AL, Malaweera ASN, Lota AS, Baskaran D, Rahman S, et al. Pocket-size hand-held cardiac ultrasound as an adjunct to clinical examination in the hands of medical students and junior doctors. Eur Heart J Cardiovasc Imaging. 2013;14(4): 323-30. https://doi.org/10.1093/ehjci/jes140.

72. Breitkreutz R, Dutiné M, Scheiermann P, Hempel D, Kujumdshiev S, Ackermann H, et al. Thorax, trachea, and lung ultrasonography in emergency and critical care medicine: assessment of an objective structured training concept. Emerg Med Int. 2013;2013:1-9. https://doi.org/10.1155/2013/312758.

73. Hamza A, Solomayer EF, Takacs Z, Juhasz-Boes I, Joukhadar R, Radosa JC, et al. Introduction of basic obstetrical ultrasound screening in undergraduate medical education. Arch Gynecol Obstet. 2016;294(3):479-85. https://doi.org/10.1007/s00404015-4002-9.

74. Amini R, Stolz LA, Hernandez NC, Gaskin K, Baker N, Sanders $\mathrm{AB}$, et al. Sonography and hypotension: a change to critical problem solving in undergraduate medical education. Adv Med Educ Pract. 2016;7:7-13. https://doi.org/10.2147/AMEP.S97491.

75. Fernández-Frackelton M, Peterson M, Lewis RJ, Pérez JE, Coates WC. A bedside ultrasound curriculum for medical students: prospective evaluation of skill acquisition. Teach Learn Med. 2007;19(1):14-9. https://doi.org/10.1207/s15328015tlm1901 4.

76. Hunter SA, Brimble J, Weatherall M, Galletly DC. Agreement of clinical measurements of liver size with ultrasound when performed by medical students. N Z Med J. 2014;127:61-9.

77. Limchareon S, Asawaworarit N, Klinwichit W, Dinchuthai P, Thomas B, Falcone RE, et al. Development of the ultrasonography learning model for undergraduate medical students: a case study of the Faculty of Medicine, Burapha University. J Chin Med Assoc. 2016;79(8):445-9. https://doi.org/10.1016/j.jcma. 2016.01.014.
78. Miner B, Purdy A, Curtis L, Simonson K, Shumway C, Baker J, et al. Feasibility study of first-year medical students identifying cardiac anatomy using ultrasound in rural Panama. World J Emerg Med. 2015;6(3):191-5. https://doi.org/10.5847/wjem.j.19208642.2015.03.005.

79. Parks AR, Verheul G, LeBlanc-Duchin D, Atkinson P. Effect of a point-of-care ultrasound protocol on the diagnostic performance of medical learners during simulated cardiorespiratory scenarios. CJEM. 2015;17(3):1-7. https://doi.org/10.1017/cem.2014.41.

80. Strnad M, Zadel S, Klemenc-Ketis Z, Prosen G. Identification of lung sliding: a basic ultrasound technique with a steep learning curve. Signa Vitae. 2013;8(1):31-5.

81. Wright SA, Bell AL. Enhancement of undergraduate rheumatology teaching through the use of musculoskeletal ultrasound. Rheumatology. 2008;47(10):1564-6. https://doi.org/10.1093/ rheumatology/ken324.

82. Amini R, Stolz LA, Breshears E, Patanwala AE, Stea N, Hawbaker N, Thompson M, Sanders AB, Adhikari S. Assessment of ultrasound-guided procedures in preclinical years. Intern Emerg Med. 2016. https://doi.org/10.1007/s11739-0161525-4.

83. Brascher A-K, Blunk JA, Bauer K, Feldmann R, Benrath J. Comprehensive curriculum for phantom-based training of ultrasound-guided intercostal nerve and stellate ganglion blocks. Pain Med. 2014;15(10):1647-56. https://doi.org/10.1111/pme. 12365.

84. Osborn S, Borhart J, Antonis M. Medical students benefit from the use of ultrasound when learning peripheral IV techniques. Crit Ultrasound J. 2012;4(1):2-2. https://doi.org/10.1186/2036-79024-2.

85. Griswold-Theodorson S, Hannan H, Handly N, Pugh B, Fojtik J, Saks M, et al. Improving patient safety with ultrasonography guidance during internal jugular central venous catheter placement by novice practitioners. Simul Healthc. 2009;4(4):212-6. https://doi. org/10.1097/SIH.0b013e3181b1b837.

86. Miller R, Ho H, Ng V, Tran M, Rappaport D, Rappaport WJA, et al. Introducing a fresh cadaver model for ultrasound-guided central venous access training in undergraduate medical education. West J Emerg Med. 2016;17(3):362-6. https://doi.org/10. 5811/westjem.2016.3.30069.

87. Hoyer R, Means R, Robertson J, Rappaport D, Schmier C, Jones $\mathrm{T}$, et al. Ultrasound-guided procedures in medical education: a fresh look at cadavers. Intern Emerg Med. 2016;11(3):431-6. https://doi.org/10.1007/s11739-015-1292-7.

88. McCrary HC, Krate J, Savilo CE, Tran MH, Ho HT, AdamasRappaport WJ, Viscusi RK, Dillon MF, Hill ADK, Quinn CM, Al E, Rubin E, Mennemeyer ST, Desmond RA, Al E, Gresens AA, Britt RC, Feliberti EC, Al E, Meng K, Lipson JA, Hoover S, Berry MP, Rossick L, Al E, Hassard MK, McCurdy LI, Williams JCA, Al E, Dunnington GL, DiMaggio PJ, Waer AL, Desmarais TJ, Al E, Mendiratta-Lala M, Williams T, Quadros ND, Al E, Ahrar JU, Ahrar K, Helbich TH, Matzek W, Fuchsjäger MH, Damera A, Evans AJ, Cornford EJ, Al E, Bennett IC, Greenslade J, Chiam H, Cho HW, Kim J, Choi J, Al E, Handa U, Tiwari A, Singhal N, Al E, Johnson PT, Nazarian LN, Feld RI, Al E, Jung AS, Sharma G, Maceri D, Al E, Sites BD, Gallagher JD, Cravero J, Al E, Mrug M, Bissler JJ, Dawoud D, Lyndon W, Mrug S, Al E, Lewis CE, Peacock WJ, Tillou A, Al E, Mitchell EL, Sevdalis N, Arora S, Al E, Varga S, Smith J, Minneti M, Al E, Castle SM, Gorbatiy V, Salas N, Al E, Zaia BE, Briese B, Williams SR, Al E, Avery DM, Champney TH. Development of a fresh cadaver model for instruction of ultrasound-guided breast biopsy during the surgery clerkship: pre-test and post-test results among third-year medical students. Am J Surg. 2016;0 (0):701707. https://doi.org/10.1016/j.amjsurg.2016.02.008. 
89. Stone MB, Moon C, Sutijono D, Blaivas M. Needle tip visualization during ultrasound-guided vascular access: short-axis vs longaxis approach. Am J Emerg Med. 2010;28(3):343-7. https://doi. org/10.1016/j.ajem.2008.11.022.

90. Tabas JA, Rosenson J, Price DD, Rohde D, Baird CH, Dhillon N. A comprehensive, unembalmed cadaver-based course in advanced emergency procedures for medical students. Acad Emerg Med. 2005;12(8):782-5. https://doi.org/10.1197/j.aem.2005.04.004.

91. Vitto MJ, Myers M, Vitto CM, Evans DP. Perceived difficulty and success rate of standard versus ultrasound-guided peripheral intravenous cannulation in a novice study group: a randomized crossover trial. J Ultrasound Med. 2016;35(5):895-8. https://doi.org/ 10.7863/ultra.15.06057.

92. Dinh VA, Dukes W, Prigge J, Avila M (2015) Ultrasound integration in undergraduate medical education: comparison of ultrasound proficiency between trained and untrained medical students. J Ultrasound Med.

93. Hempel D, Stenger T, Campo Dell' Orto M, Stenger D, Seibel A, Röhrig S, et al. Analysis of trainees' memory after classroom presentations of didactical ultrasound courses. Crit Ultrasound J. 2014;6(1):10. https://doi.org/10.1186/2036-7902-6-10.

94. Kim SC, Hauser S, Staniek A, Weber S. Learning curve of medical students in ultrasound-guided simulated nerve block. J Anesth. 2014;28(1):76-80. https://doi.org/10.1007/s00540-013-1680-y.

95. Filipiak-Strzecka D, John B, Kasprzak J, Michalski B, Lipiec P. Pocket-size echocardiograph - a valuable tool for nonexperts or just a portable device for echocardiographers? Adv Med Sci. 2013;58(1):67-72. https://doi.org/10.2478/v10039-012-0054-2.

96. Jamniczky HA, Cotton D, Paget M, Ramji Q, Lenz R, McLaughlin K, et al. Cognitive load imposed by ultrasoundfacilitated teaching does not adversely affect gross anatomy learning outcomes. Anat Sci Educ. 2016;8:197-204. https://doi.org/10. 1002/ase.1642.

97. Jamniczky HA, McLaughlin K, Kaminska ME, Raman M, Somayaji R, Wright B, et al. Cognitive load imposed by knobology may adversely affect learners' perception of utility in using ultrasonography to learn physical examination skills, but not anatomy. Anat Sci Educ. 2014;8(3):197-204. https://oi.org/10. 1002/ase.1467.

98. Gradl-Dietsch G, Korden T, Modabber A, Sönmez TT, Stromps JP, Ganse B, et al. Multidimensional approach to teaching anatomy-do gender and learning style matter? Ann Anat. 2016; https://doi.org/10.1016/j.aanat.2016.03.002.

99. Bahner DP, Jasne A, Boore S, Mueller A, Cortez E. The ultrasound challenge. J Ultrasound Med. 2013;31(12):2013-6.

100. Connolly K, Beier L, Langdorf M, Anderson C, Fox J. Ultrafest: a novel approach to ultrasound in medical education leads to improvement in written and clinical examinations. West J Emerg Med. 2015;16(1):143-8. https://doi.org/10.5811/westjem.2014. 11.23746.

101. Cortez EJ, Boulger CT, Eastin T, Adkins EJ, Granitto E, Pollard K, et al. The ultrasound challenge 2.0: introducing interinstitutional competition in medical student ultrasound education. J Ultrasound Med. 2014;33(12):2193-6. https://doi.org/10.7863/ultra.33.12. 2193

102. Dubosh NM, Kman N, Bahner D. Ultrasound interest group: a novel method of expanding ultrasound education in medical school. Crit Ultrasound J. 2011;3(3):131-4. https://doi.org/10. 1007/s13089-011-0088-x.

103. Bahner DP, Adkins E, Patel N, Donley C, Nagel R, Kman NE. How we use social media to supplement a novel curriculum in medical education. Med Teach. 2012;34(6):439-44. https://doi. org/10.3109/0142159X.2012.668245.

104. Kusunose K, Yamada H, Suzukawa R, Hirata Y, Yamao M, Ise T, et al. Effects of transthoracic echocardiographic simulator training on performance and satisfaction in medical students. J Am Soc
Echocardiogr. 2016;29(4):375-7. https://doi.org/10.1016/j.echo. 2015.12.002.

105. Bentley S, Mudan G, Strother C, Wong N. Are live ultrasound models replaceable? Traditional versus simulated education module for FAST exam. West J Emerg Med. 2015;16(6):818-22. https://doi.org/10.5811/westjem.2015.9.27276.

106. Moak JH, Larese SR, Riordan JP, Sudhir A, Yan G. Training in transvaginal sonography using pelvic ultrasound simulators versus live models: a randomized controlled trial. Acad Med. 2014;89(7): 1063-8. https://doi.org/10.1097/ACM.0000000000000294.

107. Parks AR, Atkinson P, Verheul G, Leblanc-Duchin D. Can medical learners achieve point-of-care ultrasound competency using a high-fidelity ultrasound simulator?: a pilot study. Crit Ultrasound J. 2013;5(1):9-9. https://doi.org/10.1186/2036-7902-5-9.

108. Damewood S, Jeanmonod D, Cadigan B. Comparison of a multimedia simulator to a human model for teaching FAST exam image interpretation and image acquisition. Acad Emerg Med. 2011;18(4):413-9. https://doi.org/10.1111/j.1553-2712.2011. 01037.x.

109. Weidenbach M, Wild F, Scheer K, Muth G, Kreutter S, Grunst G, et al. Computer-based training in two-dimensional echocardiography using an echocardiography simulator. J Am Soc Echocardiogr. 2005;18(4):362-6. https://doi.org/10.1016/j.echo. 2004.10.025.

110. Heer IM, Middendorf K, Müller-Egloff S, Dugas M, Strauss A. Ultrasound training: the virtual patient. Ultrasound Obstet Gynecol. 2004;24(4):440-4. https://doi.org/10.1002/uog.1715.

111. Yoo MC, Villegas L, Jones DB. Basic ultrasound curriculum for medical students: validation of content and phantom. J Laparoendosc Adv Surg Tech A. 2004;14(6):374-9. https://doi. org/10.1089/lap.2004.14.374.

112. McVicar J, Niazi AU, Murgatroyd H, Chin KJ, Chan VW. Novice performance of ultrasound-guided needling skills. Reg Anesth Pain Med. 2015;40(2):150-3. https://doi.org/10.1097/AAP. 0000000000000209.

113. Collins GB, Fanou EM, Young J, Bhogal P. A comparison of freehand vs laser-guided long-axis ultrasound techniques in novice users. Br J Radiol. 2013;86(1029):20130026. https://doi.org/10. 1259/bjr.20130026.

114. Luyet C, Hartwich V, Urwyler N, Schumacher PM, Eichenberger U, Vogt A. Evaluation of a novel needle guide for ultrasoundguided phantom vessel cannulation. Anaesthesia. 2011;66(8): 715-20. https://doi.org/10.1111/j.1365-2044.2011.06781.x.

115. Benninger B. Google glass, ultrasound and palpation: the anatomy teacher of the future? Clin Anat. 2015;28(2):152-5. https://doi. org/10.1002/ca.22480.

116. Sheehan FH, Ricci MA, Murtagh C, Clark H, Bolson EL. Expert visual guidance of ultrasound for telemedicine. J Telemed Telecare. 2010;16(2):77-82. https://doi.org/10.1258/jtt.2009. 090313.

117. Hempel D, Sinnathurai S, Haunhorst S, Seibel A, Michels G, Heringer F, Recker F, Breitkreutz R. Influence of case-based elearning on students' performance in point-of-care ultrasound courses. Eur J Emerg Med. 2015;1. https://doi.org/10.1097/MEJ. 0000000000000270.

118. Hughes DR, Kube E, Gable BD, Madore FE, Bahner DP. The sonographic digital portfolio: a longitudinal ultrasound image tracking program. Crit Ultrasound J. 2012;4(1):15. https://doi. org/10.1186/2036-7902-4-15.

119. Swamy M, Searle RF. Anatomy teaching with portable ultrasound to medical students. BMC Med Educ. 2012;12(1):99. https://doi. org/10.1186/1472-6920-12-99.

120. Tolsgaard MG, Madsen ME, Ringsted C, Oxlund BS, Oldenburg A, Sorensen JL, et al. The effect of dyad versus individual simulation-based ultrasound training on skills transfer. Med Educ. 2015;49(3):286-95. https://doi.org/10.1111/medu.12624. 
121. Nikendei C, Kraus B, Schrauth M, Weyrich P, Zipfel S, Herzog W, et al. Integration of role-playing into technical skills training: a randomized controlled trial. Med Teach. 2007;29(9):956-60. https://doi.org/10.1080/01421590701601543.

122. Blickendorf JM, Adkins EJ, Boulger C, Bahner DP. Trained simulated ultrasound patients: medical students as models, learners, and teachers. J Ultrasound Med. 2013;33(1):35-8. https://doi.org/ 10.7863/ultra.33.1.35.

123. Florescu CC, Mullen JA, Nguyen VM, Sanders BE, Vu PQ. Evaluating didactic methods for training medical students in the use of bedside ultrasound for clinical practice at a Faculty of Medicine in Romania. J Ultrasound Med. 2015;1873-1882. https://doi.org/10.7863/ultra.14.09028.

124. Vollman A, Hulen R, Dulchavsky S, Pinchcofsky H, Amponsah $D$, Jacobsen $G$, et al. Educational benefits of fusing magnetic resonance imaging with sonograms. J Clin Ultrasound. 2014;42(5):257-63. https://doi.org/10.1002/jcu.22136.

125. Oveland NP, Lossius HM, Aagaard R, Connolly J, Sloth E, Knudsen L. Animal laboratory training improves lung ultrasound proficiency and speed. J Emerg Med. 2013;45(3):e71-8. https:// doi.org/10.1016/j.jemermed.2013.03.029.

126. Jeppesen K, Bahner D. Teaching bedside sonography using peer mentoring: a prospective randomized trial. J Ultrasound Med. 2012;31(3):455-9.

127. Naeger DM, Conrad M, Nguyen J, Kohi MP, Webb EM. Students teaching students: evaluation of a "near-peer" teaching experience. Acad Radiol. 2013;20(9):1177-82. https://doi.org/10.1016/ j.acra.2013.04.004.

128. Knobe M, Munker R, Sellei RM, Holschen M, Mooij SC, Schmidt-Rohlfing B, et al. Peer teaching: a randomised controlled trial using student-teachers to teach musculoskeletal ultrasound. Med Educ. 2010;44(2):148-55.

129. Kühl M, Wagner R, Bauder M, Fenik Y, Riessen R, LammerdingKöppel M, et al. Student tutors for hands-on training in focused emergency echocardiography - a randomized controlled trial. BMC Med Educ. 2012;12(1):101. https://doi.org/10.1186/14726920-12-101.

130. Dickerson J, Paul K, Vila P, Whiticar R. The role for peer-assisted ultrasound teaching in medical school. Clin Teach. 2016;13:1-5. https://doi.org/10.1111/tct.12541.

131. Ahn JS, French AJ, Thiessen MEW, Kendall JL. Training peer instructors for a combined ultrasound/physical exam curriculum. Teach Learn Med. 2014;26(3):292-5. https://doi.org/10.1080/ 10401334.2014.910464.

132. Fox J, Chiem A, Rooney K, Maldonaldo G. Web-based lectures, peer instruction and ultrasound-integrated medical education. Med Educ. 2012;46(11):1109-10. https://doi.org/10.1111/medu.12039.

133. Tolsgaard MG, Todsen T, Sorensen JL, Ringsted C, Lorentzen T, Ottesen B, et al. International multispecialty consensus on how to evaluate ultrasound competence: a Delphi consensus survey. PLoS One. 2013;8(2):e57687. https://doi.org/10.1371/journal.pone. 0057687.

134. Tolsgaard MG, Ringsted C, Dreisler E, Klemmensen A, Loft A, Sorensen JL, et al. Reliable and valid assessment of ultrasound operator competence in obstetrics and gynecology. Ultrasound Obstet Gynecol. 2014;43(4):437-43. https://doi.org/10.1002/uog. 13198.

135. Todsen T, Tolsgaard MG, Olsen BH, Henriksen BM, Hillingso JG, Konge L, et al. Reliable and valid assessment of point-of-care ultrasonography. Ann Surg. 2015;261(2):309-15. https://doi.org/ 10.1097/sla.0000000000000552. 